\title{
Fatores dificultadores e facilitadores para reavaliação dos bens móveis na administração pública
}

\author{
Complicating and facilitating factors for revaluation of movable assets in public administration
}

Factores que complican y facilitan la revalorización de bienes muebles en la administración pública

Recebido: 07/022022 | Revisado: 14/02/2022 | Aceito: 16/02/2022 | Publicado: 25/02/2022

\author{
Matheus Viana Araujo \\ ORCID: https://orcid.org/0000-0002-0962-3779 \\ Universidade Federal de Sergipe, Brasil \\ E-mail: matheusvianamm@hotmail.com \\ Kleverton Melo de Carvalho \\ ORCID: https://orcid.org/0000-0003-1969-7955 \\ Universidade Federal de Sergipe, Brasil \\ E-mail: kleverton1@academico.ufs.br \\ Rosângela Sarmento Silva \\ ORCID: https://orcid.org/0000-0002-3044-9699 \\ Universidade Federal de Sergipe, Brasil \\ E-mail: rosangelasarmento13@academico.ufs.br
}

\begin{abstract}
Resumo
O objetivo geral desta pesquisa é analisar os fatores dificultadores e facilitadores para reavaliação dos bens móveis na Universidade Federal de Sergipe. O estudo é de cunho qualitativo, descritivo e utiliza o método de estudo de caso único para entender e descrever a experiência dos servidores no processo de reavaliação. Para análise dos dados utilizou-se a técnica da análise de conteúdo. $\mathrm{O}$ resultado da pesquisa identificou os fatores dificultadores e facilitadores do levantamento patrimonial e para a delimitação do valor de mercado, além disso, foram propostos subsídios ao processo de reavaliação dos bens móveis em uma instituição de ensino superior federal, conforme exigências das portarias 184/2008 do Ministério da Fazenda e 548/2015 da Secretaria do Tesouro Nacional. Concluiuse que é importante um levantamento patrimonial confiável e um inventário físico feito com responsabilidade, que a grande quantidade e variedade de bens da UFS torna inviável a pesquisa de preço e de mercado para todos os bens da instituição, que é fundamental uma cultura de reavaliação não restrita à comissão e que deve ser incentivada a participação dos servidores em cursos de capacitação.
\end{abstract}

Palavras-chave: Fatores dificultadores e facilitadores; Reavaliação; Bens móveis.

\begin{abstract}
The main purpose of the revaluation is to generate, on the part of the Public Administration, adjustments to the equity accounting procedures, in particular the measurement of assets at market value. The general objective of this research is to analyze the hindering and facilitating factors for the revaluation of movable assets at the Federal University of Sergipe. The study is qualitative, descriptive and uses the single case study method to understand and describe the employees' experience in the reassessment process. For data analysis, the content analysis technique was used. The result of the research identified the hindering and facilitating factors of the patrimonial survey and for the delimitation of the market value, in addition, subsidies were proposed for the process of revaluation of movable assets in a federal higher education institution, as required by ordinances 184/2008 of the Ministry of Finance and 548/2015 of the National Treasury Department. It was concluded that it is important to carry out a reliable asset survey and a physical inventory carried out with responsibility, that the large quantity and variety of UFS assets makes price and market research unfeasible for all the institution's assets, that a culture of reassessment not restricted to the commission and that the participation of civil servants in training courses should be encouraged.
\end{abstract}

Keywords: Complicating and facilitating factors; Revaluation; Movable property.

\section{Resumen}

El objetivo general de esta investigación es analizar los factores que obstaculizan y facilitan la revalorización de los bienes muebles en la Universidad Federal de Sergipe. El estudio es cualitativo, descriptivo y utiliza el método de estudio de caso único para comprender y describir la experiencia de los empleados en el proceso de reevaluación. Para el análisis de los datos se utilizó la técnica de análisis de contenido. El resultado de la investigación identificó los factores obstaculizadores y facilitadores del relevamiento patrimonial y para la delimitación del valor de mercado, además, se propusieron subsidios para el proceso de revalorización de bienes muebles en una institución de educación superior federal, de acuerdo con los requisitos de ordenanzas 184/2008 del Ministerio de Hacienda y 548/2015 de la 
Secretaría del Tesoro Nacional. Se concluyó que es importante realizar un relevamiento de activos confiable y un inventario físico realizado con responsabilidad, que la gran cantidad y variedad de activos de la UFS hace inviable la investigación de precios y mercados para todos los activos de la institución, que una cultura de revalorización no restringida a la comisión y que se fomente la participación de los funcionarios en los cursos de formación.

Palabras clave: Factores que complican y facilitan; Revalorización; Bienes muebles.

\section{Introdução}

Esta pesquisa aborda os fatores dificultadores e facilitadores para reavaliação dos bens móveis na Administração Pública. O grande fim da reavaliação é gerar por parte da Administração Pública adequações aos procedimentos contábeis patrimoniais, em especial a mensuração dos bens ao valor de mercado. Muitos dos ativos das instituições públicas estão registrados no patrimônio e na contabilidade por valores irrisórios e a avaliação de ativos pelo custo histórico apresenta limitações em seu poder informacional devido à defasagem de valor. Assim, a reavaliação restabelece o valor real dos bens utilizados pela instituição (Schvirck \& Giasson, 2008; Amaral \& Borba, 2012; Bernardes \& Colossi, 2014).

Há exigências legais para tais adequações. Inicialmente, vale menção à portaria do Ministério da Fazenda (MF) nº 184, de 25 de agosto de 2008, que determina à Secretaria do Tesouro Nacional (STN), a identificação das necessidades de convergência às normas internacionais de contabilidade, a edição de normativos, manuais, instruções de procedimentos contábeis e Plano de Contas Nacional, bem como a adoção de procedimentos necessários para atingir os objetivos de convergência estabelecidos no âmbito do Comitê Gestor da Convergência no Brasil (Brasil, 2008).

Diante desse contexto, o Conselho Federal de Contabilidade - CFC, em 2008, elaborou as Normas Brasileiras de Contabilidade Aplicadas ao Setor Público (NBC T 16.1 a NBC T 16.10), visando a convergência das Normas Brasileiras de Contabilidade aos padrões internacionais de contabilidade. De maneira mais específica, as NBC T 16.9 e 16.10 estabeleceram critérios e procedimentos para o registro, avaliação e mensuração do patrimônio público (CFC, 2012). Em 2016, o CFC, iniciou a tradução das International Public Sector Accounting Standards (IPSAS), e a elaboração das Normas Brasileiras de Contabilidade Técnicas do Setor Público (NBC TSP). Por esse caminho, faz-se prioritária a modernização dos procedimentos relacionados aos bens móveis de natureza pública.

Antes tais fatos e considerando que os procedimentos de reavaliação se aplicam a todas as entidades do setor público, inclusive, às universidades federais brasileiras, evidenciou-se a seguinte questão de pesquisa: quais fatores dificultadores e facilitadores para reavaliação dos bens móveis na Administração Pública? Assim, o objetivo do presente estudo é analisar os fatores dificultadores e facilitadores para reavaliação dos bens móveis na Universidade Federal de Sergipe (UFS).

A pesquisa se justifica por diferentes relevâncias. Os procedimentos mais relacionados à contabilidade pública estão no cerne do debate para a modernização do país e, neste sentido, este trabalho busca contribuir, considerando os princípios da eficiência e transparência, no âmbito da Administração Pública. O contexto divergente em cada entidade da Administração Pública enseja que o processo de reavaliação dos bens móveis deve seguir um modelo de relatório próprio, atrelado às suas realidades patrimoniais e contábeis, de acordo com os procedimentos técnicos e com a legislação vigente.

Tal falta de padronização é pano de fundo para diferentes gargalos, que merecem ser destacados. Há dificuldades históricas no tocante ao processo de reavaliação dos bens móveis. Segundo Bernardes e Colossi (2014), os gestores universitários não percebem a devida valorização e o cuidado no controle dos recursos materiais, como os bens móveis. Amaral e Borba (2012) enfatizam que a mudança nos formatos da contabilidade pública exige reestruturação e/ou implementação de controles, que em alguns casos, são complexos e que o processo de reavaliação demanda, dentre outros, recursos, pessoal qualificado e metodologia específica para cada tipo de ativo a ser reavaliado.

Para Padrones, Colares e Santos (2014), a falta de servidor, treinamento, clareza nos normativos da STN e a falta de conscientização da importância da implementação das NBC TSP pelos gestores, dentre outras, são as principais dificuldades na 
implementação das Normas Brasileiras de Contabilidade Aplicadas ao Setor Público, dentre elas, as que tratam da reavaliação dos bens. Corroborando essas dificuldades, Martins e Peixe (2020), demonstram que apenas $61 \%$ dos 50 profissionais envolvidos com o setor contábil, das Universidades ou Institutos Federais do Brasil pesquisadas, realizam o procedimento de reavaliação em suas instituições.

Considerando que as pesquisas e os trabalhos anteriores não demonstram as dificuldades e facilidades que os atores envolvidos enfrentam para reavaliar os bens móveis da entidade. O presente estudo mostra-se pioneiro nisso, buscando contribuir para que profissionais da área contábil e patrimonial das universidades federais possam desenvolver procedimentos internos com maior eficiência a partir das dificuldades e facilidades aqui relatadas.

Como principal pressuposto sugerimos que existem algumas dificuldades principais no processo de reavaliação dos bens móveis da UFS. A primeira é de ordem cultural, pois, os servidores da instituição não possuem a cultura de reavaliação dos bens móveis, e apresentam dificuldade no entendimento dos normativos vigentes. A segunda é de ordem processual, visto que a UFS ainda não possui um modelo de relatório que possibilite o registro das reavaliações. Como elemento facilitador, acreditamos que o sistema a ser utilizado (Sistema Integrado de Patrimônio, Administração e Contratos - SIPAC) é adequado e que pode disponibilizar o relatório de reavaliação dos bens móveis, o qual será desenvolvido pelos servidores da comissão.

\section{Metodologia}

Esta pesquisa tem como objetivo analisar os fatores dificultadores e facilitadores para reavaliação dos bens móveis na Universidade Federal de Sergipe (UFS). A metodologia utilizada é apresentada na seguinte ordem: delineamento da pesquisa; unidade caso e unidades de análise; coleta de dados; protocolo do estudo de caso; instrumento de pesquisa; análise e interpretação dos dados e modelo teórico-empírico da pesquisa.

O estudo é de cunho qualitativo, pois, procura compreender o fenômeno investigado a partir da percepção dos participantes, descritivo, por apresentar um relato detalhado do fenômeno, bem como a complexidade da situação (Godoy et al., 2010) e utiliza o método de estudo de caso único, considerado o mais adequado, pois, busca entender um fenômeno contemporâneo em seu contexto da vida real (Yin, 2015). Além disso, é necessário entender e descrever a experiência dos servidores da Universidade Federal de Sergipe (UFS), participantes da comissão de reavaliação, e de três servidores, que não fazem parte da comissão formalizada pela Reitoria, mas que estão envolvidos e acompanham o processo de reavaliação dos bens móveis, como também a elaboração do relatório (Marques et al., 2015).

Sobre a unidade-caso e unidades de análise, delineou-se a Universidade Federal de Sergipe. Trata-se de uma Fundação Pública, instituída pelo Decreto-lei $\mathrm{n}^{\circ} 269$ de 28 de fevereiro de 1967 e instalada oficialmente em 15 de maio de 1968. Portanto é uma instituição que tem 53 anos de contribuição no âmbito do ensino, pesquisa e extensão no Estado de Sergipe. Pertencem ao seu organograma, dentre outras, a Pró-Reitoria de Administração (PROAD), o Departamento de Recursos Financeiros (DEFIN), a Divisão de Contabilidade (DICON), a Divisão de Patrimônio (DIPATRI) e a Superintendência de Tecnologia da Informação (STI) (Universidade Federal de Sergipe [UFS], 2021).

Todos os setores supracitados, foram inseridos como unidades de análise, visto que estão envolvidos no processo de reavaliação dos bens móveis na universidade e elaboração do relatório de reavaliação. Diante do que recomenda Yin (2015), o método de estudo de caso único foi escolhido por ser um caso comum. Segundo o autor, este tipo de caso visa proporcionar informações sobre os processos relacionados a algum interesse teórico.

Os sujeitos desta pesquisa são os servidores da comissão para reavaliação dos bens móveis na UFS, dos quais: dois pertencem à DICON, um à DIPATRI. Além deles, um servidor da STI, o Pró-reitor da PROAD e a diretora do DEFIN, que não fazem parte da comissão. Assim, cada servidor e setor pertencente às unidades de análise foi importante para o processo de reavaliação diante das funções desempenhadas na instituição, tendo em vista o cargo no qual ocupam. 
Quanto à coleta de dados e para responder ao problema de pesquisa, foi seguido o que recomenda Yin (2015). Dessa forma, foram utilizadas várias fontes de evidências: a) análise documental (manual de contabilidade, normas de contabilidade, mensagens da setorial de contabilidade do Ministério da Educação (MEC) e Portaria de formação da comissão, composta por servidores da UFS; b) entrevista semiestruturada, com seis servidores envolvidos no processo de reavaliação e c) observação participante (anotações dos debates ocorridos durante as reuniões online) na comissão de reavaliação dos bens móveis permanentes da UFS.

Ainda de acordo com Yin (2015), para condução da pesquisa e orientação do pesquisador, é necessário a elaboração do protocolo do estudo de caso como instrumento de pesquisa, o qual deve conter os procedimentos e regras gerais a serem seguidas, vide Tabela 1.

Tabela 1: Protocolo do estudo de caso.

\begin{tabular}{|c|c|}
\hline Categorias & Especificação \\
\hline $\begin{array}{l}\text { Visão geral do } \\
\text { estudo de caso } \\
\text { e finalidade do } \\
\text { protocolo }\end{array}$ & $\begin{array}{l}\text { Este estudo de caso tem a finalidade de analisar os fatores dificultadores e facilitadores para reavaliação dos bens } \\
\text { móveis na Universidade Federal de Sergipe (UFS); } \\
\text { Dessa forma, o presente protocolo serviu para orientar o pesquisador em cada fase indispensável à realização desta } \\
\text { pesquisa; }\end{array}$ \\
\hline $\begin{array}{l}\text { Procedimentos } \\
\text { de coleta de } \\
\text { dados }\end{array}$ & $\begin{array}{l}\text { Análise e interpretação documental (Manual de Contabilidade Aplicada ao Setor Público (MCASP) e Normas } \\
\text { Brasileiras de Contabilidade Técnicas do Setor Público (NBC TSP)); } \\
\text { Análise documental (mensagens da setorial de contabilidade/Ministério da Educação (MEC) e Portaria } n^{\circ} 32 \text { de } \\
\text { janeiro de } 2021 \text { de formação da comissão de reavaliação; } \\
\text { Entrevista semiestruturada com seis servidores; } \\
\text { Observação participante (anotações dos debates ocorridos nas reuniões online) na comissão de reavaliação dos bens } \\
\text { móveis permanentes da UFS. }\end{array}$ \\
\hline $\begin{array}{l}\text { Questões de } \\
\text { estudo de caso }\end{array}$ & $\begin{array}{l}\text { Quais as normas e legislações vigentes relacionadas ao objetivo da pesquisa? } \\
\text { Quais são as orientações das normas e manual para reavaliação dos bens móveis, que devem ser seguidas pela } \\
\text { comissão formada pela UFS? } \\
\text { Quais os fatores dificultadores e facilitadores no processo de reavaliação dos bens? } \\
\text { Além daqueles que participam da comissão de reavaliação dos bens móveis, quais os servidores, relevantes à pesquisa, } \\
\text { deverão ser entrevistados? } \\
\text { Quais subsídios poderão ser propostos para que a gestão da reavaliação dos bens móveis se dê de maneira sistêmica, } \\
\text { eficiente e contínua na UFS? }\end{array}$ \\
\hline $\begin{array}{l}\text { Guia para o } \\
\text { relatório de } \\
\text { estudo de caso }\end{array}$ & $\begin{array}{l}\text { O relatório do estudo de caso abordará uma narrativa simples e descritiva para analisar o caso. } \\
\text { Dessa forma, para responder o objetivo da pesquisa, ele será elaborado visando detalhar as evidências obtidas por meio } \\
\text { da análise documental, das entrevistas semiestruturadas, bem como por meio da observação participante. }\end{array}$ \\
\hline
\end{tabular}

Fonte: Elaborado pelos autores com base em Yin (2015).

Para responder aos objetivos desta pesquisa foi utilizado o seguinte instrumento de pesquisa, conforme Tabela 2. O qual demonstra o roteiro da entrevista semiestruturada e a observação participante, composto por cinco seções, tais como: 1) Perfil dos atores; 2) Levantamento patrimonial 3) Delimitação do Valor de Mercado; 4) Proposição de Subsídios e 5) Observação Participante. 
Tabela 2: Instrumento de pesquisa.

\begin{tabular}{|c|c|c|c|}
\hline $\begin{array}{c}\text { Elementos de } \\
\text { Análise }\end{array}$ & Categorias Analíticas & Preâmbulo & $\begin{array}{c}\text { Fundamentação } \\
\text { Teórica }\end{array}$ \\
\hline Perfil dos Atores & $\begin{array}{l}\text { Cargo e setor dos atores e importância deles (cargo e } \\
\text { setor) para a comissão de reavaliação; } \\
\text { Relação do cargo e do setor com o processo de } \\
\text { reavaliação dos bens móveis na UFS; } \\
\text { Experiência e competências técnicas com reavaliação } \\
\text { de bens móveis. }\end{array}$ & $\begin{array}{l}\text { Foi formada uma comissão para } \\
\text { realizar a reavaliação dos bens } \\
\text { móveis na Universidade Federal } \\
\text { de Sergipe (UFS) e elaboração do } \\
\text { relatório de reavaliação. }\end{array}$ & $\begin{array}{l}\text { Portaria } n^{\circ} 32 \text { de } \\
\text { fevereiro de } 2021 .\end{array}$ \\
\hline $\begin{array}{l}\text { Levantamento } \\
\text { Patrimonial }\end{array}$ & $\begin{array}{l}\text { Dificuldades e/ou facilidades encontrados nessa etapa } \\
\text { inicial; } \\
\text { Se possui conhecimento do que recomenda o MCASP } \\
\text { quanto à baixa dos bens inservíveis e quanto ao decreto } \\
\mathrm{n}^{\circ} 9.373 / 2018 \text {, que define o que pode ser considerado } \\
\text { bens inservíveis; } \\
\text { Fatores dificultadores e facilitadores para realizar a } \\
\text { baixa dos bens móveis inservíveis da UFS; } \\
\text { Fatores dificultadores ou facilitadores para } \\
\text { estabelecimento dos critérios de reavaliação dos bens } \\
\text { móveis antigos e irrisórios da UFS; }\end{array}$ & $\begin{array}{l}\text { O levantamento dos bens móveis } \\
\text { a serem reavaliados é uma etapa } \\
\text { importante no processo de } \\
\text { reavaliação. }\end{array}$ & $\begin{array}{lr}\text { Fernandes } & \text { e } \\
\text { Monteiro } & (2019) ; \\
\text { MCASP } & (2018) \text {. } \\
\text { Decreto } & \mathrm{n}^{\circ} \\
9.373 / 2018 & \end{array}$ \\
\hline $\begin{array}{l}\text { Delimitação } \\
\text { Valor } \\
\text { Mercado }\end{array}$ & $\begin{array}{l}\text { Dificuldades ou facilidades, para realizar a delimitação } \\
\text { do valor de mercado dos bens móveis da UFS; } \\
\text { Fatores que dificultam ou facilitam o consenso entre os } \\
\text { setores e os servidores na determinação dos critérios de } \\
\text { reavaliação; }\end{array}$ & $\begin{array}{l}\text { Conforme o Manual de } \\
\text { Contabilidade Aplicada ao Setor } \\
\text { Público (MCASP) para que } \\
\text { ocorra a reavaliação, os bens } \\
\text { devem ser mensurados ao valor } \\
\text { de mercado (valor justo). Além } \\
\text { disso, exige que a comissão } \\
\text { formada elabore um relatório de } \\
\text { avaliação com informações, } \\
\text { como: os critérios utilizados para } \\
\text { a avaliação do bem e sua } \\
\text { respectiva fundamentação. }\end{array}$ & $\begin{array}{l}\text { Amaral e Borba } \\
(2012) \text {; Bernardes e } \\
\text { Colossi (2014); } \\
\text { MCASP (2018). }\end{array}$ \\
\hline
\end{tabular}

Se os servidores possuem a cultura de reavaliação dos bens móveis ou um relatório que subsidie o processo; o que pode ajudá-los; se há incentivos ou capacitação continuada; se participou de algum curso ou treinamento relacionado à reavaliação, ao conhecimento das normas e legislações; e como esse Proposição de entendimento ajudaria no andamento da reavaliação; Subsídios Se existe dificuldade no entendimento das normas atuais;

Os benefícios da integração entre os setores para o

A proposição de subsídios para que a gestão da reavaliação dos bens móveis se dê de maneira sistêmica, eficiente e contínua, no âmbito da UFS é um dos Autores. objetivos desta pesquisa. andamento do processo de reavaliação dos bens móveis;

Se o sistema (SIPAC) utilizado pela UFS, que disponibilizará o relatório, é adequado e suficiente.

\begin{tabular}{llll}
\hline $\begin{array}{l}\text { Observação } \\
\text { Participante }\end{array}$ & $\begin{array}{l}\text { Pontos surgidos e mais discutidos nos debates, durante } \\
\text { as reuniões da comissão. }\end{array}$ & Y..... & Yin (2015). \\
\hline
\end{tabular}

Fonte: Elaborado pelos autores com base nos dados da pesquisa (2021).

Para o tratamento dos dados relacionados ao objetivo desta pesquisa, utilizou-se a técnica da análise de conteúdo, a qual, conforme Bardin (2015), é um conjunto de técnicas de análise das comunicações que utiliza procedimentos sistemáticos e objetivos de descrição do teor das mensagens. Assim, é possível inferir e interpretar o conteúdo delas (Bardin, 2015).

Importante salientar, que para a análise de conteúdo, foi realizada uma pré-análise e organização de todo material. Em seguida, foram feitas as transcrições, codificação e categorização dos dados coletados. Por fim, realizou-se o tratamento dos 
resultados e interpretação dos materiais coletados (documentos, resultados das entrevistas e anotações decorrentes da observação participante) (Bardin, 2015).

Por fim, considerando que esta pesquisa se trata de um estudo de caso único e integrado, as unidades de análise são os setores envolvidos e que acompanham o processo de reavaliação dos bens móveis na UFS, sendo eles: a PROAD, o DEFIN, a DICON, a DIPATRI e a STI (Yin, 2015). Pode-se considerar este delineamento o mais adequado para o alcance do objetivo desta pesquisa, pois o modelo proposto na Figura 1 assinala, por meio das linhas pontilhadas, que os limites entre o caso e contexto provavelmente não são rígidos (Yin, 2015), visto que a realidade deste caso poderá ser coincidente em quaisquer outras instituições de ensino superior federal.

Figura 1: Método teórico da pesquisa.

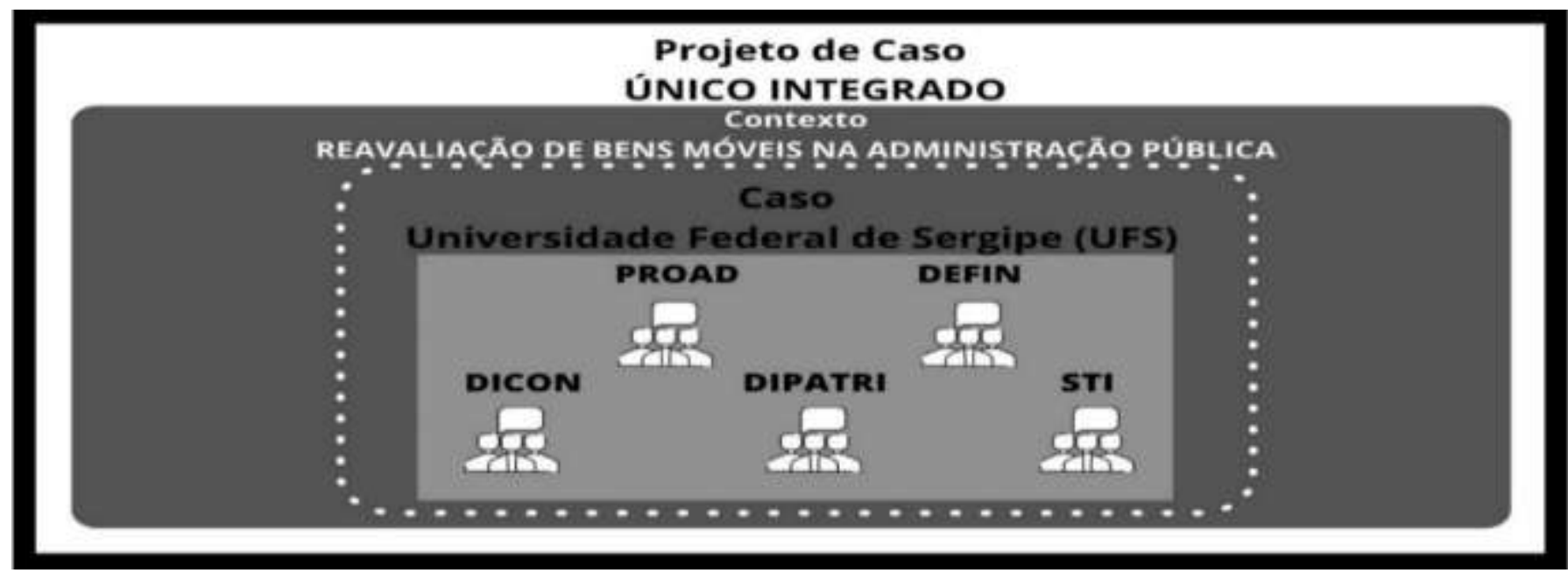

Fonte: Elaborado pelos autores com base em Yin (2015).

\section{Resultados e Discussão}

\subsection{Exigência, cumprimento e início do processo de reavaliação}

Nesta seção são discutidos a exigência, cumprimento e início do processo de reavaliação dos bens móveis na Universidade Federal de Sergipe (UFS). As mensagens 2016/0568359 e 2016/0568387 da Setorial de Contabilidade/MEC, encaminharam informações a fim de subsidiar o cumprimento dos prazos estabelecidos pela Portaria $\mathrm{n}^{\circ} 548$ de 24 de setembro de 2015 para implantação dos Procedimentos Contábeis Patrimoniais - PCP. Nesse sentido, informaram que é necessária a adoção dos PCP, tomando por base o inventário realizado no encerramento do exercício, na época 2015, e que é fundamental a existência de um sistema informatizado para avaliação dos bens, bem como para ajustá-los ao valor de mercado.

Diante das exigências, as mensagens trataram como imprescindível à compreensão e correta implantação dos procedimentos patrimoniais, a leitura das normas da Secretaria do Tesouro Nacional (STN) e do Manual de Contabilidade Aplicada ao Setor Público (MCASP), dentre outros. Dessa forma, perante a obrigatoriedade, necessidade de ajuste contábil e para execução da reavaliação, foi publicada a Portaria ${ }^{\circ} 32$ de 12 de janeiro de 2021 , que cria a comissão de reavaliação dos bens móveis permanentes da UFS (UFS, 2021).

\subsection{Levantamento patrimonial}

Neste subcapítulo são demonstrados os fatores dificultadores e facilitadores encontrados durante o processo de levantamento patrimonial. Antes disso, para uma melhor compreensão do processo de reavaliação, foram elaborados dois fluxos dos temas debatidos nas reuniões da comissão que podem serem vistos a seguir nas Figuras 2 e 3. 
Figura 2: Fluxo da gestão patrimonial dos bens móveis a serem reavaliados e dos bens inservíveis.

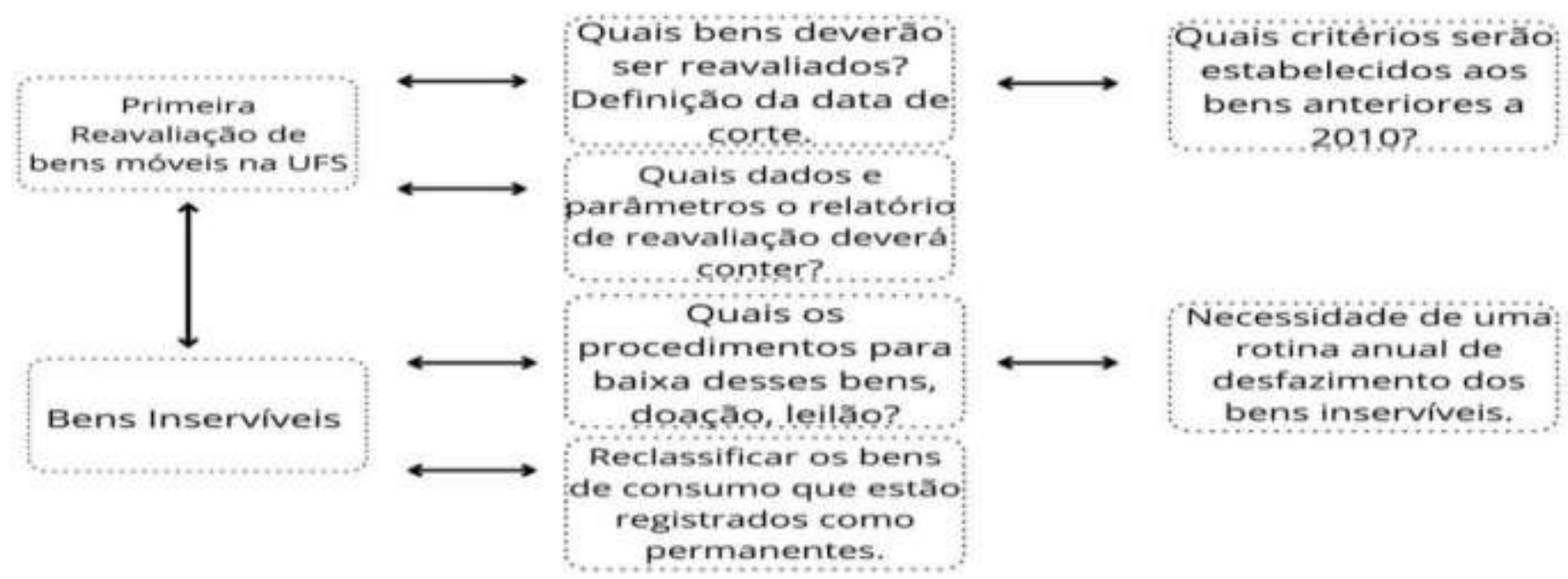

Fonte: Dados da pesquisa (2021).

A Figura 2 demonstra os debates ocorridos no início do processo de reavaliação. Questionamentos quanto à definição data de corte (a partir de que ano os bens serão reavaliados); critérios a serem utilizados para os bens registrados antes de 2010; os parâmetros a serem definidos no relatório de reavaliação; os procedimentos de baixa dos bens inservíveis e quanto a necessidade de uma rotina de desfazimento; por fim, reclassificação dos bens registrados como permanentes, mas que são de consumo.

Figura 3: Fluxo da gestão patrimonial dos bens móveis antigos e irrisórios e sua relação com o valor de mercado.

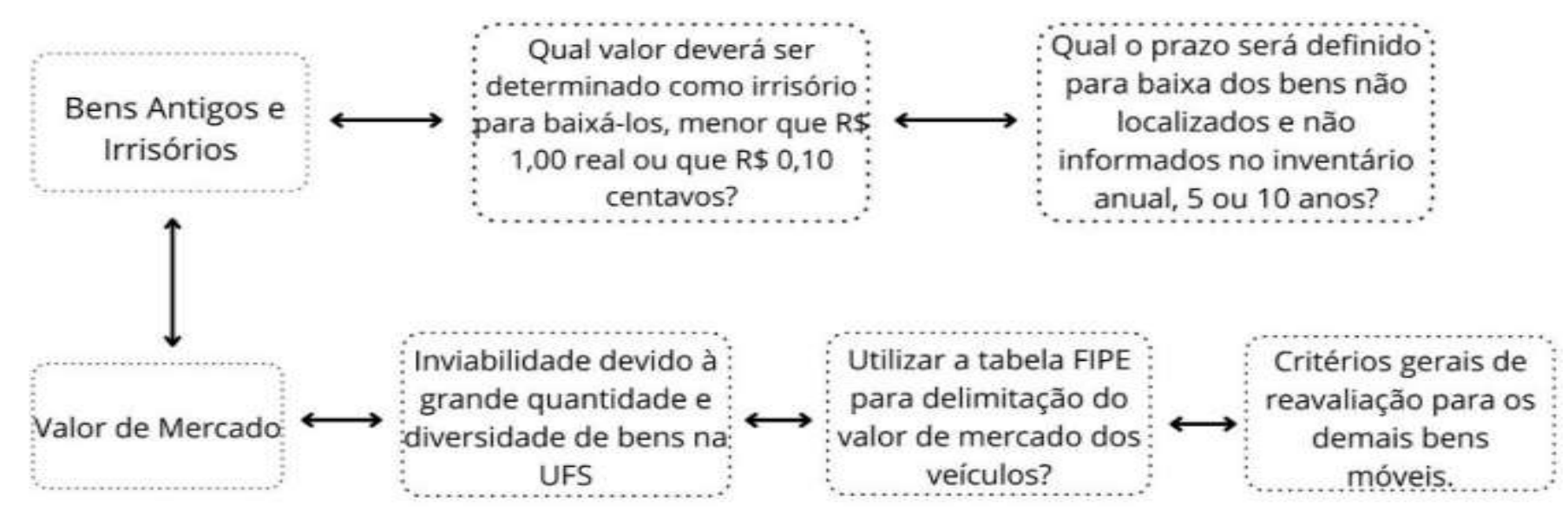

Fonte: Dados da pesquisa (2021).

A Figura 3 retrata as discussões para estabelecer o valor máximo dos bens a serem tratados como irrisórios; o prazo que o bem não informado no inventário anual seria tratado como não localizado e posteriormente baixado; inviabilidade da definição do valor de mercado para todos os bens da UFS; debates quanto a utilização da tabela FIPE para os veículos e critérios gerais para os demais bens móveis.

Conforme o Manual de Contabilidade Aplicada ao Setor Público (MCASP), de forma geral, a Administração Pública não aplicava os critérios de reconhecimento e mensuração do ativo imobilizado. Assim, inicialmente, o manual recomenda a definição da data de corte (ano que a instituição estabelecerá como início da aplicação dos procedimentos contábeis patrimoniais de reavaliação, depreciação, dentre outros), bem como uma verificação no inventário da instituição para realizar a baixa dos bens que não estejam sendo utilizados e não tenham valor de venda por serem inservíveis (Brasil, 2018). 
Nesse sentido, a primeira dificuldade encontrada pelos servidores é a quantidade de itens não localizados na universidade, o que demanda um trabalho árduo na localização desses bens junto aos setores, outro fator, é identificar os bens que estão cadastrados como permanentes, mas que devem ser reclassificados para bens de consumo. Dessa forma, é mais difícil trabalhar quando não há uma garantia da situação real do patrimônio. De forma oposta, segundo os entrevistados, o que facilitou os trabalhos da comissão foi trabalhar apenas com aqueles bens informados no inventário.

Outro fator que emergiu foi a grande quantidade e variedade (tipos) dos bens da UFS, por exemplo, equipamentos de laboratórios, hospitalares, de salas de aula e da parte administrativa. Esta situação dificulta o estabelecimento de critérios de reavaliação, além disso, alguns bens devem seguir um critério específico devido às suas características. Amaral e Borba (2012), destacam que a quantidade de bens a serem reavaliados e a complexidade deste procedimento, exige dos servidores envolvidos reciclagens, capacitação técnica e orientações. Para os entrevistados, o fator que facilitou a comissão no estabelecimento de critérios foi ter disponível em relatórios patrimoniais informações como o estado do bem, o valor de entrada, dentre outras.

Quanto aos bens inseríveis, deve-se tratar novamente do inventário patrimonial, segundo Fernandes e Monteiro (2019), os bens móveis ficarão sob responsabilidade de algum setor ou servidor até que ocorra a sua baixa. A deficiência deste procedimento na universidade, devido à grande movimentação entre os setores, à falta de consciência e importância pelos servidores e setores responsáveis pelos bens cadastrados na sua carga patrimonial, dificulta a identificação e localização desses bens.

Além disso, um fator identificado foi que, apesar de existir um galpão para bens inservíveis na universidade, em razão da grande quantidade de itens, necessita-se de uma equipe focada em separar os itens por lotes, recolhimento nos setores, catalogação e realização do processo de desfazimento, o que não é tão simples. Outrossim, não há uma rotina anual de baixa desses bens por leilão ou doação, aumentando a quantidade de itens nessa situação.

Diante do que foi exposto, para os servidores, existe um fator dificultador na emissão de um relatório fidedigno que retrate os bens inservíveis, se o bem realmente existe e o seu valor correto. Entretanto, para eles o que facilitou os trabalhos da comissão foi iniciar o processo de desfazimento, a fim de diminuir a carga patrimonial de bens a serem analisados e reavaliados.

Em relação aos bens antigos e irrisórios, para os entrevistados uma das dificuldades da comissão é determinar como serão tratados os bens anteriores a 2010, visto que eles não eram depreciados e por serem bens cadastrados há muito tempo no sistema, a qualidade das informações é precária, os dados são antigos e faltam informações relevantes. Esta dificuldade pode ser percebida no estudo de Moreira, Corrêa e Alencar (2015), ao destacarem que apenas 22 das 38 Universidades Federais, que responderam ao questionário, estão em processo de reavaliação dos bens adquiridos antes de 2010.

Um fator dificultador relatado pelos entrevistados, é a grande quantidade e variedade de bens com valor até $\mathrm{R} \$ 0,10$ centavos. Silva, Macedo, Sauerbronn e Szuster (2012) no estudo de caso realizado sobre avaliação de ativos imobilizados, em uma organização militar da marinha do Brasil, também destacam a grande quantidade de bens registrados com valores irrisórios, defasados e, portanto, abaixo do valor de mercado. Amaral e Borba (2012), destacam essa situação na Universidade Federal de Santa Catarina (UFSC), ao relatarem a heterogeneidade e antiguidade dos bens irrisórios registrados no ativo imobilizado da instituição. Segundo os autores, estes fatores dificultam a apuração do valor justo pela equipe.

Nesse sentido, para os servidores envolvidos no processo de reavaliação, o levantamento e emissão de um relatório patrimonial com informações desses bens, sua localização e existência física é fundamental ao andamento da comissão. Estas informações são necessárias para o estabelecimento do valor de mercado deles, por serem antigos, e se ainda estão disponíveis para uso. 
Asim, de acordo com os entrevistados, a comissão precisa de informações detalhadas desses bens, no entanto percebem que há uma deficiência no cadastro e que faltam informações relevantes ao processo de reavaliação, como por exemplo a característica e o tipo de bem. Entretanto, para eles, há informações disponíveis e dados informatizados, que favoreceram o andamento da comissão, como por exemplo o estado do bem (ocioso, em uso, ótimo, bom ou regular).

Por fim, um fator dificultador no levantamento patrimonial refere-se à diversidade de bens na instituição e delimitação da vida útil remanescente ou futura do bem. De acordo com os entrevistados, a dificuldade é determinar a vida útil futura desses bens antigos ou com valores irrisórios, que ainda servem à instituição e devem continuar na base de dados, quais critérios serão utilizados, ficando a cargo da comissão defini-los.

O que facilitou o andamento da comissão, segundo os servidores, foi o uso de trabalhos de outras instituições como base para o estabelecimento dos critérios de reavaliação, a exemplo do trabalho realizado pela comissão de reavaliação de bens materiais do Tribunal de Contas do Estado de Rondônia (TCE RO). A seguir, apresenta-se de forma detalhada os aspectos avaliados com os respectivos fatores dificultadores e facilitadores, conforme Tabela 3.

Tabela 3: Fatores dificultadores e facilitadores para o levantamento patrimonial.

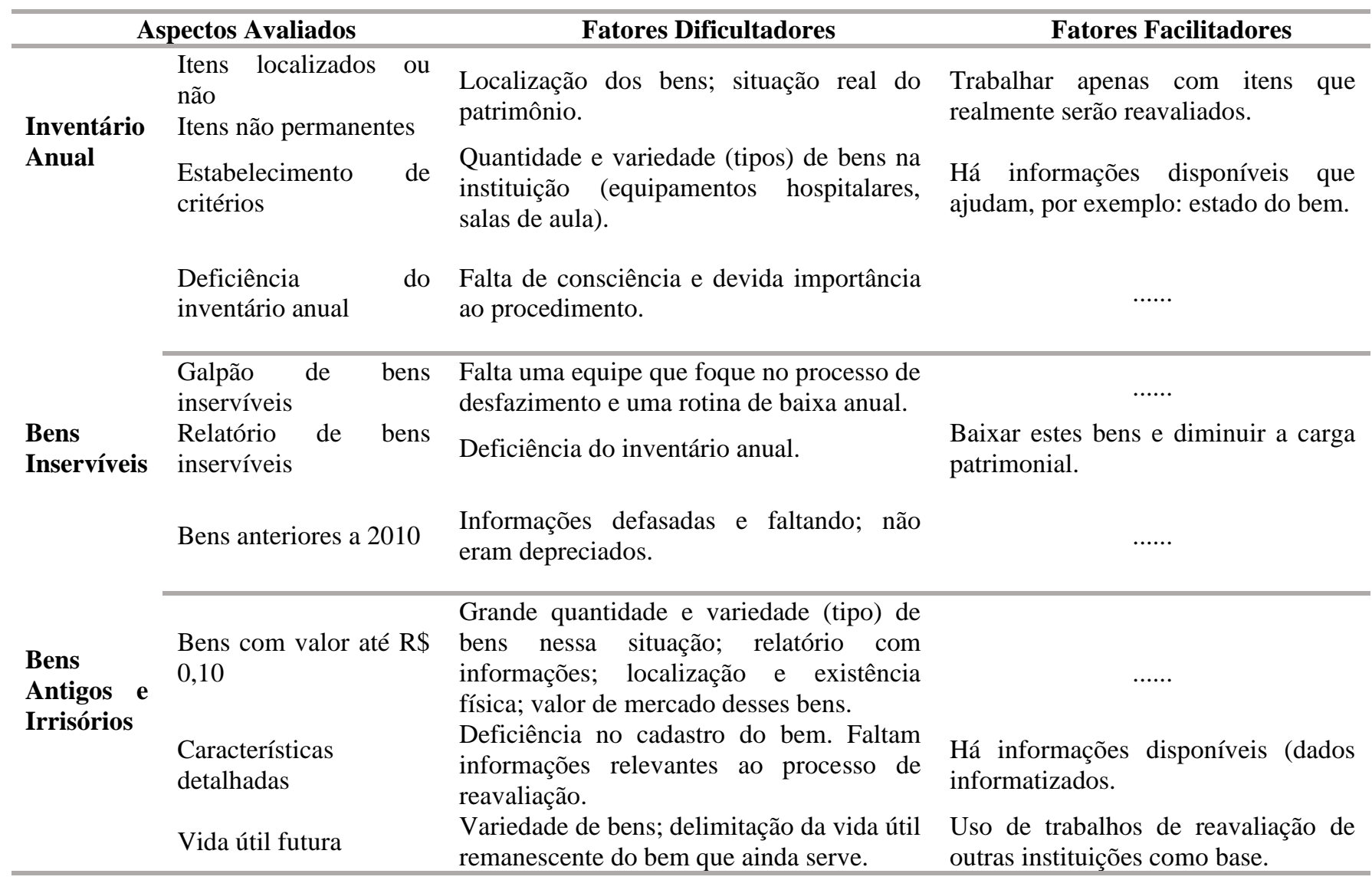

Fonte: Dados da pesquisa (2021).

\subsection{Delimitação do valor de mercado}

Conforme a NBC TSP - Estrutura Conceitual, o valor de mercado fornece informação útil, pois reflete adequadamente o valor do ativo à instituição (CFC, 2016). Dessa forma, a Tabela 4 demonstra os aspectos avaliados bem como os fatores dificultadores e facilitadores encontrados na delimitação do valor de mercado dos bens móveis. 
Tabela 4: Fatores dificultadores e facilitadores para delimitar o valor de mercado.

\begin{tabular}{|c|c|c|c|}
\hline Aspec & os Avaliados & Fator Dificultador & Fator Facilitador \\
\hline \multirow{2}{*}{$\begin{array}{l}\text { Valor de } \\
\text { Mercado }\end{array}$} & $\begin{array}{l}\text { Critérios } \\
\text { técnicos }\end{array}$ & $\begin{array}{l}\text { Entendimento e lacuna das normas } \\
\text { Quantidade e diversidade de bens; servidores } \\
\text { disponíveis; bens antigos. }\end{array}$ & $\begin{array}{l}\text { Uso de trabalhos de reavaliação de outras } \\
\text { instituições como base; } \\
\text { Tabela FIPE para Veículos }\end{array}$ \\
\hline & $\begin{array}{l}\text { Consenso entre } \\
\text { os setores e } \\
\text { servidores }\end{array}$ & $\begin{array}{l}\text { Entendimento e interpretação das normas; vida } \\
\text { útil do bem após ser reavaliado; trabalho remoto e } \\
\text { pandemia (COVID-19). }\end{array}$ & Integração e boa relação; olhar diferenciado. \\
\hline
\end{tabular}

Fonte: Dados da pesquisa (2021).

De acordo com a Tabela 4, percebe-se que o entendimento dos critérios técnicos, quanto ao valor de mercado dos bens móveis, configura-se como um fator dificultador. Para os entrevistados, o fato de existir uma deficiência, ou lacuna das normas, dificultou o trabalho da comissão, tendo em vista a especificidade da UFS, ou seja, grande quantidade e variedade (natureza, vida útil e desgastes diferentes) de bens. Isso torna inviável a pesquisa de mercado e de preços de todos os bens pelos servidores disponíveis.

Silva et al. (2012) destacam essa dificuldade no estudo de caso realizado em uma organização militar da marinha do Brasil. De acordo com os autores, a avaliação de 2.516 ativos foi uma atividade difícil, sendo necessários aproximadamente 4 meses, tendo em vista as inadequações no registro de alguns itens e a necessidade de uma análise in loco. Outra dificuldade apontada nas entrevistas é a delimitação do valor de mercado dos bens antigos, que estão conservados e sendo utilizados, por ser complexo encontrar bens similares no mercado. Um facilitador é a existência da tabela FIPE para delimitar o valor de mercado dos veículos, bem como, novamente, o uso de trabalhos de outras instituições como base para o estabelecimento dos critérios de reavaliação, a exemplo do trabalho realizado pela comissão de reavaliação de bens materiais do TCE RO.

Importante destacar que, segundo os entrevistados, a dificuldade no entendimento e interpretação das normas quanto à reavaliação, procedimento relativamente novo e complexo na Administração Pública, dificultou o consenso entre os servidores. Amaral e Borba (2012), destacam que no setor governamental os procedimentos devem estar de acordo com a lei. Entretanto, a legislação é difícil de entender e dispersa, o que demanda interpretações oficiais.

Nesse sentido, conforme exposto pelos entrevistados, foram necessários maiores debates, demonstrações e esclarecimentos, a fim de ajustar e alinhar todos os participantes. Um exemplo disso, foram as constantes discussões sobre como definir a vida útil dos bens após serem reavaliados. De acordo com o MCASP, a entidade deve utilizar o prazo de vida útil conforme as peculiaridades de sua gestão (Brasil, 2018). Para Bernardes e Colossi (2014), após a reavaliação dos bens, a depreciação deverá ser contabilizada sobre o novo valor, levando-se em conta a vida útil econômica remanescente indicada no laudo.

Por fim, outro dificultador explicitado por alguns entrevistados, que dificultou, em certos momentos, os trabalhos da comissão tem sido a pandemia (COVID-19) e o trabalho remoto, visto que por motivos relacionados ao momento, os encontros da comissão foram postergados, impossibilitando a discussão e elaboração dos critérios de reavaliação. Por fim, para os eles, a boa relação e integração, com olhares técnicos diferenciados sobre reavaliação de bens móveis, foram fatores que facilitaram o consenso entre os setores e servidores.

\subsection{Proposição de subsídios para a gestão da reavaliação dos bens móveis}

De acordo com a NBC TSP 07 - Ativo Imobilizado, a reavaliação deve ser realizada com regularidade para que o valor contábil do ativo não seja diferente do seu valor justo na data das demonstrações contábeis (CFC, 2017). Nesse sentido, 
objetivando recomendar e destacar os subsídios para que o processo de reavaliação no âmbito da UFS se dê de maneira sistêmica, contínua e eficiente, demonstram-se na Tabela 5 as ações e os benefícios à reavaliação dos bens móveis.

Tabela 5: Proposição de subsídios à reavaliação dos bens móveis.

\begin{tabular}{cc}
\hline Ações & Benefícios à reavaliação dos bens móveis \\
\hline Desenvolvimento da cultura de reavaliação & Continuidade \\
Revisão dos critérios estabelecidos & Continuidade \\
Foco nos trabalhos da comissão & Sistêmica \\
Incentivo dos gestores (respaldo) & Eficiente \\
Capacitação dos servidores & Eficiente \\
\hline Integração entre os setores e servidores & Eficiente \\
Sistema Informatizado & Sistêmica \\
\hline
\end{tabular}

Fonte: Dados da pesquisa (2021).

Para Padrones et al. (2014), em uma pesquisa realizada com contadores do setor público na esfera federal, estadual e municipal, constatou-se que apenas $16 \%$ das 274 respostas implementaram totalmente a NBC T 16.10, que se refere à avaliação e mensuração de ativos e passivos. Na pesquisa de Raminho e Colares (2016), apenas 25\% das 44 Universidades Federais, que responderam ao questionário, realizam a reavaliação dos bens móveis.

Além disso, constataram que nessas instituições o procedimento é feito com base no relatório emitido pela comissão de servidores, designadas por autoridade competente. Nesse sentido, de acordo com os entrevistados desta pesquisa, por ser a primeira reavaliação dos bens móveis na UFS, não há uma cultura de reavaliação e um relatório que subsidie. No entanto, posteriormente, esta pesquisa recomenda que haja essa cultura e atualização dos bens por mais servidores da universidade, ou seja, não restrito à comissão de reavaliação, devido à grande quantidade e diversidade de bens no âmbito da instituição.

Outro subsídio recomendado, atrelado à continuidade, é o fato de que os critérios a serem definidos pela comissão deverão ser mantidos, ajustados e reexecutados anualmente, para bens que tenham mudanças significativas de valores ou em um prazo maior, definido pela comissão, para os demais. Assim, estará de acordo com a NBC TSP 07 - Ativo Imobilizado, a qual informa que a "frequência das reavaliações depende das mudanças no valor justo dos itens do ativo imobilizado que estão sendo reavaliados" (CFC, 2017 p. 10).

Para que a reavaliação seja feita de maneira sistêmica, esta pesquisa sugere que os participantes da comissão tenham foco no trabalho de reavaliação, sendo dispensados, temporariamente, das atividades diárias ou que seja delineada uma rotina, dias efetivos para os trabalhos da comissão, pesquisa e aprendizado sobre o assunto.

Importante salientar, que os incentivos dos gestores, que acompanham o processo de reavaliação, são fundamentais à eficiência e à conclusão dos trabalhos da comissão, bem como de todos os envolvidos no processo de reavaliação. Dessa forma, o respaldo, a participação e a disposição deles para solucionar qualquer fator dificultador é fundamental. Na pesquisa realizada por Padrones et al. (2014), constatou-se que 60,6\% das 274 respostas obtidas, relataram que a falta de conscientização da importância pelos gestores é um fator dificultador na implementação das NBC TSP.

Quanto à capacitação dos servidores envolvidos no processo de reavaliação dos bens móveis, acredita-se que a participação de todos, ou de alguns, que fossem posteriormente multiplicadores, em cursos para conhecimento das normas, legislações e procedimentos de reavaliação facilita e ajudará, quando outra comissão for formada, o andamento dos trabalhos, definição dos critérios e tomada de decisões com mais segurança. 
Moreira et al. (2015), relatam essa percepção ao afirmarem em sua pesquisa, que 92,1\% das 38 Universidades Federais concordam que a necessidade de treinamento e capacitação de pessoal é uma limitação à convergência dos procedimentos patrimoniais às normas internacionais de contabilidade.

Outro ponto importante, sugerido por este por este artigo, é a contínua integração entre os setores e servidores no processo de reavaliação. Pois, de acordo com os entrevistados, este fator facilita a fluidez dos trabalhos, a comunicação e o saneamento das dúvidas, visto que cada um contribui tecnicamente com conhecimentos técnicos da sua área, seja ela patrimonial, tecnológica ou contábil. Na pesquisa realizada por Fernandes e Monteiro (2019), em um Instituto Federal, identificou-se que a distância entre o setor de patrimônio e o contador, além da ausência de um sistema informatizado, dificultam o controle patrimonial.

Por fim, diante da necessidade de um sistema informatizado para realizar a reavaliação, conforme as mensagens da setorial de contabilidade/MEC, os servidores entrevistados entendem que o Sistema Integrado de Patrimônio, Administração e Contratos (SIPAC) é suficiente e adequado para disponibilizar o relatório de reavaliação dos bens móveis, para eles apenas pequenas alterações pontuais serão necessárias, uma vez que mudanças nos critérios de reavaliação, das normas contábeis e legislações poderão surgir.

\section{Conclusão}

Diante de tudo que foi discutido, os objetivos desta pesquisa foram atendidos, visto que conseguiu identificar as dificuldades e facilidades relacionadas ao processo de reavaliação dos bens móveis na UFS. Além disso, as proposições foram confirmadas: os servidores da instituição não possuem a cultura de reavaliação dos bens móveis e apresentam dificuldade no entendimento dos normativos vigentes; a universidade ainda não possui um modelo de relatório que possibilite o registro das reavaliações; e o sistema a ser utilizado, SIPAC, é considerado adequado para disponibilizar o relatório de reavaliação dos bens móveis, a ser desenvolvido pela comissão.

Dentre as principais dificuldades encontradas no processo de reavaliações dos bens móveis na UFS, destaca-se a deficiência de informações no levantamento patrimonial e a delimitação do valor de mercado, tendo em vista a grande quantidade e variedades de bens. Resta evidente a importância de um levantamento patrimonial confiável e de um inventário físico feito com responsabilidade, que forneçam o máximo de ferramentas para garantir a qualidade das informações e auxiliar não só o trabalho da comissão de reavaliação, como também outros que venham solicitar relatórios patrimoniais.

Assim, a entrada do bem, as informações quanto aos valores, a vida útil e a inclusão das características devem ser criteriosas desde o seu registro. A presente pesquisa, também descreve a relação existente entre servidores disponíveis e a grande quantidade e variedade de bens no âmbito da universidade. Esta relação demonstrou ser inviável a pesquisa de preço e de mercado para todos os bens da instituição.

Dessa forma, é fundamental que a cultura de reavaliação dos bens móveis não seja restrita à comissão. Outro ponto demonstrado foi a importância do respaldo e disposição dos gestores, bem como o incentivo à participação em cursos de capacitação pelos servidores envolvidos no processo de reavaliação, sendo fundamental ao entendimento das normas e aplicação prática. Por fim, ficou evidente a importância da integração entre os setores de patrimônio, contabilidade e tecnologia da informação para um melhor desempenho dos trabalhos da comissão de reavaliação dos bens móveis e elaboração do relatório de reavaliação.

A partir da teoria abordada e dos conhecimentos gerados, é possível que esta pesquisa possa contribuir teoricamente com os próximos estudos sobre reavaliação dos bens móveis na Administração Pública. Além disso, contribui com o entendimento dos profissionais da área contábil e patrimonial da UFS, bem como de outras universidades federais de ensino público, que estejam realizando ou realizarão o mesmo procedimento. 
O estudo limitou-se a demonstrar os fatores que dificultam e facilitam o processo de reavaliação dos bens móveis na UFS, assim, não houve um aprofundamento no processo de controle patrimonial e a definição dos critérios de reavaliação. Por fim, são apresentadas como sugestões para pesquisas futuras: entendimento e melhorias da rotina patrimonial nas Universidades Federais, do registro ao fornecimento de relatórios patrimoniais; e os possíveis critérios e fatores de reavaliação para delimitar o valor de mercado dos bens móveis em instituições com grande quantidade e variedade de bens.

\section{Referências}

Amaral, N. A. de L., \& Borba, J. A. (2012). As Reavaliações de Ativos na Nova Contabilidade Pública: O Caso da Universidade Federal de Santa Catarina. Revista Catarinense Da Ciência Contábil, 11(33), 35-50. http://dx.doi.org/10.16930/2237-7662/rccc.v11n33p35-50.

Bardin, L. (2015). Análise de conteúdo. Edições 70.

Bernardes, J. F., \& Colossi, N. (2014). Controle dos Recusos Materiais nas Universidades: O caso da depreciação, amortização e da reavaliação dos bens móveis e imóveis. In: XIV Colóquio Internacional de Gestão Universitária - CIGU, Florianópolis, SC. https://repositorio.ufsc.br/xmlui/bitstream/handle/123456789/131472/2014-89.pdf?sequence=1\&isAllowed=y.

Brasil. Decreto n. 9.373, de 11 de maio de 2018. (2018). Dispõe sobre a alienação, a cessão, a transferência, a destinação e a disposição final ambientalmente adequadas de bens móveis no âmbito da administração pública federal direta, autárquica e fundacional. Brasília, DF. https://www.planalto.gov.br/ccivil_03/_ato2015-2018/2018/decreto/d9373.htm.

Brasil. Ministério da Fazenda. Portaria n. 184, de 25 de agosto de 2008. (2008). Dispõe sobre as diretrizes a serem observadas no setor público (pelos entes públicos) quanto aos procedimentos, práticas, elaboração e divulgação das demonstrações contábeis, de forma a torná-los convergentes com as Normas Internacionais de Contabilidade Aplicadas ao Setor Público. http://normas.receita.fazenda.gov.br/sijut2consulta/link.action?visao=anotado\&idAto=24439.

Brasil. Secretaria do Tesouro Nacional. Manual de Contabilidade Aplicada ao Setor Público (8a ed.). (2018). Aplicado à União e aos Estados, Distrito Federal e Municípios. Ministério da Fazenda. Secretaria do Tesouro Nacional. https://sisweb.tesouro.gov.br/apex/f?p=2501:9::::9:P9_ID_PUBLICACAO:31484.

Brasil. Secretaria do Tesouro Nacional. Portaria n. 548, de 24 de setembro de 2015. (2015). Dispõe sobre prazos-limite de adoção dos procedimentos contábeis patrimoniais aplicáveis aos entes da Federação, com vistas à consolidação das contas públicas da União, dos estados, do Distrito Federal e dos municípios, sob a mesma base conceitual. https://siconfi.tesouro.gov.br/siconfi/pages/public/conteudo/conteudo.jsf?id=23.

CFC - Conselho Federal De Contabilidade. (2012). Normas Brasileiras de Contabilidade: Contabilidade Aplicada ao Setor Público: NBCs T 16.1 a 16.11. http://www.cofen.gov.br/wp-content/uploads/2016/08/NBCT-16_1-a-16_11_Setor_P\%C3\%BAblico.pdf.

CFC - Conselho Federal De Contabilidade. (2016). NBC T SP Estrutura Conceitual - Estrutura Conceitual para Elaboração e Divulgação de Informação Contábil de Propósito Geral pelas Entidades do Setor Público. https://www1.cfc.org.br/sisweb/SRE/docs/NBCTSPEC.pdf.

CFC - Conselho Federal De Contabilidade. (2017). Norma Brasileira de Contabilidade. NBC TSP 07 - Ativo Imobilizado, de 22 de setembro de 2017. https://www1.cfc.org.br/sisweb/SRE/docs/NBCTSP07.pdf.

Fernandes, E. C., \& Monteiro, D. (2019). Análise do Controle Patrimonial de Bens Permanentes em uma Organização Pública. Administração Pública E Gestão Social, 4(11), 1-23. https://doi.org/10.21118/apgs.v4i11.7224.

Godoy; C. K., Bandeira-de-Melo, R., \& Silva, A. B. (2010). Pesquisa Qualitativa em Estudos Organizacionais: Paradigmas, Estratégias e Métodos, (2a. ed.). São Paulo: Editora Saraiva.

Marques, K. C. M., Camacho, R. R., \& Alcantara, C. C. V. de. (2015). Avaliação do Rigor Metodológico de Estudos de Caso em Contabilidade Gerencial Publicados em Periódicos no Brasil. Revista Contabilidade \& Finanças, 26(67), 27-42. https://doi.org/10.1590/rcf.v26i67.98096.

Martins, A. D., \& Peixe, B. C. S. (2020). Percepção dos procedimentos de mensuração do Ativo Imobilizado nas instituições públicas de ensino superior. CAFI, 4(1), 74-93. https://doi.org/10.23925/cafi.v4i1.49779.

Moreira, J. S., Corrêa, D. M. M. C., \& Alencar, R.C. (2015, 31 de maio a 03 de junho). Convergência da Contabilidade Pública aos Padrões Internacionais: Um estudo da adoção no imobilizado e intangível nas universidades federais brasileiras. In: IX Congresso ANPCONT, Curitiba, PR. http://anpcont.org.br/pdf/2015/CPT320.pdf.

Padrones, K. G. S. A., Colares, A. C. V., \& Santos, W. J. L. (2014, novembro). Análise do grau de implantação das IPSAS nas entidades públicas brasileiras e suas principais limitações no processo. Anais do Congresso Brasileiro de Custos-ABC, Natal, RN. https://anaiscbc.emnuvens.com.br/anais/article/view/3771/3772.

Raminho, A. H., \& Colares, A. C. V. (2016). Disclosure Da Informação Contábil Na Gestão Patrimonial Dos Bens Móveis Das Instituições Públicas De Ensino Superior Federais Brasileiras. ConTexto, 16(33), 113-127. https://seer.ufrgs.br/ConTexto/article/view/56909/pdf.

Schvirck, E., \& Giasson, O. R. (2008). Perfil Econômico-Financeiro De Empresas Que Fazem E Que Não Fazem Reavaliação De Ativos. BBR - Brazilian Business Review, 5(3), 255-270. https://www.redalyc.org/pdf/1230/123012563006.pdf.

Silva, A. C., Macedo, M. A. S., Sauerbronn, F. F., \& Szuster, N. (2012, julho/setembro). Avaliação de Ativos Imobilizados no Setor Público: Estudo de Caso em uma Organização. 
Research, Society and Development, v. 11, n. 3, e32911326690, 2022

(CC BY 4.0) | ISSN 2525-3409 | DOI: http://dx.doi.org/10.33448/rsd-v11i3.26690

Universidade Federal de Sergipe - UFS. (2021). Acesso à Informação: informações básicas. https://acessoainformacao.ufs.br/pagina/5934.

Universidade Federal de Sergipe - UFS. Gabinete do Reitor. Portaria n. 32, de 12 de janeiro de 2021. (2021). https://www.sipac.ufs.br/public/jsp/boletim_servico/busca_avancada.jsf .

Yin, R. K. (2015). Estudo de caso: planejamento e métodos, (5a ed.). Bookman. 